\title{
Fuga fúnebre, de Paul Celan
}

Karin Bakke de Araújo

Escritor de língua alemã, o autor de Fuga fúnebre nasceu em 1920 na cidade de Cernauti, capital da Bukovina, então Romênia, hoje Ucrânia, filho único de pais judeus, com o nome de Paul Antschel; ou Paul Ancel, segundo a ortografia romena. O pseudônimo Paul Celan foi adotado depois da Segunda Guerra. Frequentou a escola primária alemã e depois a hebraica. Começou o curso de medicina em Tours, na França, do qual desistiu, voltando para a Romênia, para estudar Romanística. Quando, em 1940, sua cidade foi ocupada pelas tropas soviéticas, conseguiu continuar seus estudos. Porém, em 1941, sob o domínio das tropas romenas e alemãs, os judeus foram confinados num gueto. Durante esse período, Celan traduziu os Sonetos de William Shakespeare.

No ano seguinte, seus pais seriam deportados. Num campo de concentração de Transnístria, o pai morreu de tifo e a mãe, fuzilada. Celan sobreviveu em diferentes campos de trabalhos forçados. Quando, em agosto de 1944, o exército soviético assumiu o controle da região, Celan retomou seus estudos. Existem relatos de que versões iniciais do poema "Todesfuge" teriam circulado então.

Em 1948, ele se dirigiu a Viena, vindo a se estabelecer em Paris nesse mesmo ano. Nessa época, sem chamar muita atenção, foi publicado seu primeiro livro de poesias Der Sand aus den Urnen. Em 1952, é publicado em Stuttgart seu livro Mohn und Gedächtnis, que 
incluía o poema "Todesfuge". Nesse mesmo ano, ele se casou com Gisèle Lestrange; nos dezoito anos seguintes, ele produziria junto com ela uma correspondência de mais de 700 cartas. Ele trabalhava como tradutor e era professor de alemão na École Normale Supérieure, tornando-se cidadão francês em 1955. A lista de autores que traduziu é extensa, incluindo, além do já citado Shakespeare, Gillaume Apollinaire, Charles Baudelaire, Emily Dickinson, Robert Frost, Stéphane Mallarmé, Marianne Moore, Fernando Pessoa, Pablo Picasso, Arthur Rimbaud, Giuseppe Ungaretti, Paul Valéry, Sergei Yesenin e Franz Kafka, para nos limitarmos aos autores mais conhecidos entre nós.

Entre 1965 e 1966, Celan foi internado diversas vezes em clínicas psiquiátricas e, em 1967, Celan e sua esposa decidiram viver em casas separadas. Em outubro de 1969, Celan faz sua primeira e última viagem para Jerusalém. As circunstâncias e a data de sua morte são incertas. Provavelmente, no dia 20 de abril de 1970, ele buscou a morte no rio Sena, atirando-se da ponte Mirabeau. Seu corpo foi encontrado no dia $1^{\circ}$ de maio de 1970, perto de Courbevoie, a dez quilômetros de Paris.

Nada disso eu sabia quando conheci o poema "Todesfuge" e a primeira idéia que me veio é a de que eu nunca havia lido nenhuma outra obra que retratasse de forma tão pungente e definitiva a realidade de um campo de concentração nazista. Ao traduzi-lo para o nosso português do Brasil, descobri que as suas imagens eram tão específicas quanto universais e que elas me agradavam transpostas para nosso idioma quotidiano, trazendo aquela realidade aparentemente distante para perto de nossos corações e de nossas mentes. Já no seu título era possível criar uma relação íntima com a nossa língua, que também emprega o termo fuga na terminologia musical. Nesse sentido, o título Fuga Fúnebre soava familiar, remetendo à expressão "marcha fúnebre", amplamente conhecida. E o poema é todo estruturado como uma peça musical, com ritmos, cadências, fugas e melodias dentro e em torno das palavras, empregando te- 
mas recorrentes, que voltam para introduzir um contratema, uma abordagem adicional. Tentei manter essas melodias, esses ritmos, esses temas encadeados em nossas palavras brasileiras.

Já nas duas primeiras palavras simples e quotidianas encontramos o absurdo absoluto da situação. Todo leite é branco, essa é a realidade de todas as manhãs. Mas na conjuntura que se introduz, o leite é preto. Instala-se a catástrofe, existe um mundo pervertido. E essa lógica pervertida foi retratada por Paul Celan com as prosaicas palavras schwarze Milch. A tradução teria que seguir esse imperativo do autor, mantendo a equivalência de branco e preto, optando-se por leite preto, que tem o mesmo efeito de choque. Para seguir qualificando esse leite, a opção foi por matinal pelo fato de essa palavra remeter à nossa refeição diária de todas as manhãs, quando é comum ser servido leite. Depois eu viria a conhecer análises sobre possíveis origens bíblicas da imagem, mas sempre guardei essa minha primeira impressão como a mais pungente. Para o termo abends, considerei particularmente indicado, nesse caso, o nosso termo de noitinha, por nos dar uma idéia daquela parte do dia em que a jornada de trabalho já terminou, mas quando ainda não é hora de dormir, trazendo uma variante para nachts que viria a seguir. Outra solução que acabei adotando como feliz foi não nos deitamos amontoados para da liegt man nicht eng, por ser uma expressão igualmente usual em nossa linguagem. Também foi possível encontrar uma boa equivalência para a expressão coloquial ihr einen ihr andern na nossa composição uns e outros.

Outra imagem que permeia toda a obra, e que lhe serve de fecho, é

dein goldenes Haar Margarete

dein aschenes Haar Zulamith

Nesse caso os termos goldenes e aschenes remetem aos cabelos loiros da alemã Margareta e aos cabelos de Sulamita, que se transformarão em cinza nos fornos crematórios. Como o adjetivo cinza 
em português designa a cor cinzenta, foi possível manter a noção da cor do cabelo das duas mulheres, juntamente com a alusão aos acontecimentos dos campos de concentração nazistas feita por Paul Celan.

\section{Todesfuge}

Schwarze Milch der Frühe wir trinken sie abends wir trinken sie mittags und morgens wir trinken sie nachts wir trinken und trinken

wir schaufeln ein Grab in den Lüften da liegt man nicht eng Ein Mann wohnt im Haus der spielt mit den Schlangen der schreibt der schreibt wenn es dunkelt nach Deutschland dein goldenes Haar Margarete

er schreibt es und tritt vor das Haus und es blitzen die Sterne er pfeift seine Rüden herbei

er pfeift seine Juden hervor lässt schaufeln ein Grab in der Erde er befiehlt uns spielt auf nun zum Tanz

Schwarze Milch der Frühe wir trinken dich nachts wir trinken dich morgens und mittags wir trinken dich abends wir trinken und trinken

Ein Mann wohnt im Haus der spielt mit den Schlangen der schreibt der schreibt wenn es dunkelt nach Deutschland dein goldenes Haar Margarete

Dein aschenes Haar Sulamith wir schaufeln ein Grab in den Lüften da liegt man nicht eng

Er ruft stecht tiefer ins Erdreich ihr einen ihr andern singet und spielt er greift nach dem Eisen im Gurt er schwingts seine Augen sind blau stecht tiefer die Spaten ihr einen ihr andern spielt weiter zum Tanz auf 
Schwarze Milch der Frühe wir trinken dich nachts wir trinken dich mittags und morgens wir trinken dich abends wir trinken und trinken ein Mann wohnt im Haus dein goldenes Haar Margarete dein aschenes Haar Sulamith er spielt mit den Schlangen

Er ruft spielt süsser den Tod der Tod is ein Meister aus Deutschland er ruft streicht dunkler die Geigen dann steigt ihr als Rauch in die Luft dann habt ihr ein Grab in den Wolken da liegt man nicht eng

Schwarze Milch der Frühe wir trinken dich nachts wir trinken dich mittags der Tod ist ein Meister aus Deutschland wir trinken dich abends und morgens wir trinken und trinken der Tod ist ein Meister aus Deutschland sein Auge ist blau er trifft dich mit bleierner Kugel er trifft dich genau ein Mann wohnt im Haus dein goldenes Haar Margarete er hetzt seine Rüden auf uns er schenkt uns ein Grab in der Luft er spielt mit den Schlangen und träumet der Tod ist ein Meister aus Deutschland

dein goldenes Haar Margarete dein aschenes Haar Sulamith 
Karin Bakke de Araújo. Fuga fúnebre, de Paul Celan

\section{Fuga fúnebre}

Leite preto matinal nós o bebemos de noitinha nós o bebemos ao meio-dia e de manhã nós o bebemos à noite bebemos e bebemos cavamos uma cova nos ares lá não nos deitamos amontoados Um homem mora na casa que brinca com as cobras que escreve que escreve ao escurecer para a Alemanha teu cabelo dourado Margareta ele o escreve e vai para frente da casa e as estrelas cintilam ele assobiando chama seus cães

assobiando chama seus judeus manda cavar uma cova na terra ele nos ordena agora toquem uma dança

Leite preto matinal nós te bebemos à noite nós te bebemos de manhã e ao meio-dia nós te bebemos de noitinha bebemos e bebemos Um homem mora na casa que brinca com as cobras que escreve que escreve ao escurecer para a Alemanha teu cabelo dourado Margareta Teu cabelo cinza Sulamita cavamos uma cova nos ares lá não nos deitamos amontoados

Ele grita cavem mais fundo na terra uns e outros cantem e toquem ele saca a arma do cinto brandindo-a seus olhos são azuis finquem mais fundo as pás uns e outros continuem a tocar uma dança

Leite preto matinal nós te bebemos à noite nós te bebemos ao meio-dia e de manhã nós te bebemos de noitinha bebemos e bebemos um homem mora na casa teu cabelo dourado Margareta teu cabelo cinza Sulamita ele brinca com as cobras 
Ele grita toquem a música da morte com mais doçura a morte é um mestre da Alemanha

ele grita tirem um som mais sombrio dos violinos e vocês subirão como fumaça para os ares

assim vocês terão uma cova nas nuvens lá ninguém se deita amontoado

Leite preto matinal nós te bebemos à noite

nós te bebemos ao meio-dia a morte é um mestre da Alemanha

nós te bebemos de noitinha e de manhã bebemos e bebemos

a morte é um mestre da Alemanha seu olho é azul

te atinge com uma bala de chumbo te acerta em cheio

um homem mora na casa teu cabelo dourado Margareta

ele incita seus cães para cima de nós ele nos presenteia com uma cova nos ares

ele brinca com as cobras e sonha a morte é um mestre da Alemanha

teu cabelo dourado Margareta

teu cabelo cinza Sulamita 
Karin Bakke de Araújo. Fuga fúnebre, de Paul Celan

\section{Referências:}

CELAN, Paul. Gesammelte Werke. Frankfurt: Suhrkamp, 1983. Erster Band. p. 41-42.

FELSTINER, John. Paul Celan. Eine Biografie. Trad. FLIESSBACH, Holger do original Paul Celan: Poet, Survivor, Jew. München: Verlag C. H. Beck, 1997.

FIGUEIREDO, Priscila. Catástrofe e exclusão. Cult, N²7, 1999. p. 44-48.

HAMBURGER, Michael. Celan Übersetzen. Tradução do inglês de Joachim Kalka. Text + Kritik. Zeitschrift für Literatur, N 53/54, 2002. p. 8-24. 